\title{
Evaluation in medical education
} KJME

Tai Young Yoon

Department of Medical Education and Medical Humanities, Kyung Hee University School of Medicine, Seoul, Korea

의학교육에서의 평가

경희대학교 의학전문대학원 의학교육 및 의인문학교실

\section{윤태영}

의학교육에서 평가는 기본적으로 학생에 대한 다양한 학습 평가와 진급사정, 기초 및 임상종합평가, 학습자에 의한 강의 나 교육과정평가, 교수에 대한 (연구, 교육, 사회봉사 등) 업 적평가와 승진심사, 크게는 의과대학 교육 전반에 대한 인증 평가와 같이 다양한 영역과 수준에서 필수적인 사항이다. 또 한 형성평가에서 총합평가로, 교과목 강의에서 통합교육으로, 기존의 강의 방식 이외의 다양한 수업방식의 시행으로 평가 방법 또한 매우 다양하다.

이번 호에는 평가와 관련된 논문 3편이 실렸는데, "의학교 육 평가도구로서의 유비쿼터스바탕검사의 유용성"[1]에서는 4 학년생들을 대상으로 스마트패드를 이용하여 임상종합평가 를 시행하면서 시행 전후에 학생 설문조사를 실시하였다. 스 마트기기를 이용하는 유비쿼터스바탕검사는 시간과 경비 절 감, 멀티미디어를 이용한 실제 임상상황 제시 가능, 시기나 장 소의 유동성과 신속하고 지속적인 문항과 피험자 관리 등의 장점으로 일부 대학에서 시도하고 있으며 우리나라 의사국가 시험에도 수년 내에 이를 도입하기 위한 준비를 하고 있다. 설
문조사 결과에서 임상 술기 평가와 학습 목표 달성에 유용성 이 있으며 기존 평가방식보다 편리하고 전반적인 구성과 완 성도에 만족하지만 기존 시험을 선호하는 의견이 많아 유비 쿼터스바탕검사 시행을 위하여 안전성 확보와 적합한 문항개 발 이외에 학생들에게 충분한 경험을 제공할 필요가 있다.

학생에 대한 평가는 오랜 경험을 가지고 있으나 수업이나 담당교수에 대한 평가는 교수업적평가의 시행과 더불어 중요 성이 커지고 관심을 기울이는 분야이다. "학생에 의한 강의평 가에 영향을 미치는 요인 분석"[2]에서는 교수업적평가에 학 생들의 강의평가 점수를 반영하면서, 교수들의 수업참여 기 회가 많지 않은 의과대학에서 강의평가의 신뢰성, 타당성, 효 과성과 관련한 연구의 필요성을 갖고 의과대학 1학년과 2학 년 강의에 대한 전임교수의 강의평가 점수를 분석하였다. 그 결과 성별, 직급, 전공과 같은 교수요인은 큰 차이가 없었으 나, 수업 시간이나 수업 방법 등 수업 요인은 강의평가 결과에 영향을 주는 것으로 나타나 강의평가 점수를 총합적 목적으 로 사용하는 데에는 고려할 부분이 있음을 알 수 있다.
Received: February 16, 2015 • Revised: February 16, 2015 • Accepted: February 16, 2015 Corresponding Author: Tai Young Yoon (http://orcid.org/0000-0002-5743-9044) Department of Medical Education and Medical Humanities, Kyung Hee University School of Medicine, 26 Kyungheedae-ro, Dongdaemun-gu, Seoul 130-701, Korea Tel: +82.2.961.0284 Fax: +82.2.969.0792 email: tyoung@khu.ac.kr
Korean J Med Educ 2015 Mar; 27(1): 1-2. http://dx.doi.org/10.3946/kjme.2015.27.1.1 eISSN: 2005-7288

(C) The Korean Society of Medical Education. All rights reserved. This is an open-access article distributed under the terms of the Creative Commons Attribution Non-Commercial License (http:// creativecommons.org/licenses/by-nc/3.0/), which permits unrestricted non-commercial use, distribution, and reproduction in any medium, provided the original work is properly cited. 
강의평가 중 동료교수가 교수수행능력을 관찰하고 평가하 는 동료평가는 평가 결과의 신뢰성이 높고 평가 교수와 피평 가 교수 모두에게 교육적 발전을 줄 수 있는 효과적인 방법이 라고 할 수 있으나 수업의 공개와 평가를 부담스러워하는 우 리나라에서는 잘 시행되지 않다가 신임교수의 교수법 개발의 일환으로 사용해 왔다. "통합교육과정에서 녹화된 강의 동영 상을 활용한 동료평가 분석 연구”[3]에서는 2학년 학생들을 대상으로 435명의 교수가 진행한 561시간의 통합교육 강의 동영상을 421명의 교수가 동료평가를 시행하였다. 평가문항 은 강의의 목적, 수준의 적절성, 분량의 적절성, 학습 목표의 유무, 목표와 내용의 일치, 사례의 제시, 명확한 언어 전달, 학 생들과의 상호작용, 핵심 요약, 전반적인 만족도 등 4점 척도 10 개 문항이었다. 조사 결과, 교수들이 대체로 통합교육의 취 지에 맞는 수업을 하고 있고 학생들에게 언어적 측면의 전달 은 잘 되고 있는 반면, 수업 종료 전 요약 정리와 수업 중 학생 들과의 상호작용이 미흡한 것으로 나타나 교수법 훈련 등 교 수개발의 필요성이 있었다.

그 동안 의학교육 영역에서 평가 목적에 맞는 평가방법을 개발하고 적용하기 위하여 많은 노력을 기울여 왔지만 완벽 한 평가방법을 갖추는 것은 완벽한 사람을 찾는 것처럼 불가 능한 일일지 모르겠다. 평가방법이나 도구의 장단점과 한계
점을 잘 이해하여 적절하게 사용하고 계속적인 개선 노력을 기울이는 것이 의학교육에 참여하는 우리 모두에게 주어진 숙제라는 생각이 든다.

Acknowledgements: None.

Funding: None.

Conflicts of interest: None.

\section{REFERENCES}

1. Kwon OY, Rhee SY, Choi JM, Kim YS. Usefulness of ubiquitous-based testing for evaluations in medical education. Korean J Med Educ 2015; 27: 3-10.

2. Chae SJ, Choung YH, Chung YS. Factors that influence student ratings of instruction. Korean J Med Educ 2015; 27: $19-25$.

3. Yoo DM, Yoon HB, Lee S. Peer review analysis of lectures using video recordings in an integrated curriculum. Korean J Med Educ 2015; 27: 11-18. 